\title{
Assessing the Quality of E-Services Software Using Artificial Intelligent Techniques
}

\author{
Osama Mohammad Rababah ${ }^{1}$ \\ ${ }^{1}$ King Abdullah II School of Information Technology, The University of Jordan, Amman, Jordan \\ Correspondence: Osama Mohammad Rababah, King Abdullah II School of Information Technology, Amman, PC \\ 11942, Amman, Jordan. Tel: 962-6-535-5000. E-mail: O.Rababah@ju.edu.jo
}

Received: August 4, 2018

doi:10.5539/mas.v12n9p242
Accepted: August 14, $2018 \quad$ Online Published: August 28, 2018

URL: https://doi.org/10.5539/mas.v12n9p242

\begin{abstract}
Computer applications, termed e-services, are being developed to offer efficient access to services, by electronic means. Quality of e-service is one of the major aspects that play a key role in the success or failure of online organizations. It improves the competitive advantages and mends the relations with clients and increases their gratifications. E-services are becoming progressively pervasive, and this development has been supplemented by augmented professional interest in measuring and handling online service quality. This interest is also echoed in a large number of academic studies. In spite of this, there is a slight agreement about the dimensions and antecedents of perceived e-service quality. Assessing e-service quality come to be industry or context dependent in which, it may raise problems to create a global measure. To tackle this issue, several website quality models have been established, with a congruently huge literature. This paper provides a review of this literature as well as recommends a new vision to develop measurement scales for e-service quality based on artificial intelligent technique.
\end{abstract}

Keywords: e-service, website evaluation, website quality, artificial intelligent, software metric

\section{Introduction}

E-service can be defined as the electronic provision of services to users (Sara et al., 2018). E-service is a Webbased service conveyed through the Internet (Bedman Narteh, 2015). According to Sara et al., (2018), an e-service operation is one where all or part of the communication between the service provider and the client is conducted over the Internet. An e-service has a 'front-end' Web-based systems and 'back-end' information systems. It also embraces the interface between them, which has a vital role in the e-service (Sara et al., 2018).

E-service quality grasped a great attention in last two decades due to its robust consequence on online organizations performance in many features like profitability, lower costs, customer satisfaction and loyalty (Iham et al., 2013; Bedman, 2015; Sara et al., 2018). There are a lot of studies that have dedicated on online service quality under the impact of service quality and information quality, with numerous methods. These comprise SERVQUAL, E-QQUAL, user-perceived web quality, online service quality, quality model for portal data, e-service quality, quality aspects in design and use of Web sites, WebQual, or consumer perspective of e-service quality (Saha and Nesa, 2011). However, among online service quality studies, few have addressed online service quality, and very few researches have been conducted using a comprehensive and integral approach to explore online service quality.

There is no consensus among scholars about e-service quality core and how to assess it. Assessing online service quality turns out to be industry or context dependent in which it may increase the problems to establish a worldwide measure.

There are a lot of scholarly models that evaluate e-service quality appeared in the last two decades. An example of those models had been verified on above 436,000 data points from 16,000 clients. What this designates is that the use of website quality scholarly models is a firm discipline. Nevertheless, numerous of these models have several dimensions, in addition to abnormally huge measure tools that require extra period for data gathering and data exploration in all measure phase, which are wastefully unaffordable to use. Furthermore, several of these models have not demonstrated precise vigorous, and display short levels of trustworthiness and cogency.

In this research, universal models for e-service assessment were recommended, using BBNs, as alternate method to the solitary models used at current. This method varies from questionnaire-based surveys methods in that it 
practices a procedure targeting to limit bias and common mistakes and offers a supple tactic to state the quality of e-service, as clients recognize it, in a short time.

\section{The Importance of E-Service Quality}

In the previous two decades, the amount of e-services delivered to clients through information and communication technologies has been growing, and it was found that online organizations digital services quality toughly touch the actual access to e-services by clients (Kumbhar, 2012). Moreover, attaining e-services quality has significantly prohibits the communication among clients and e-services.

Diverse characteristics of service quality have been addressed by many studies during the previous two decades. They usually measured service quality as a serious achievement factor for the organizations endeavors to differentiate their self from other rivals. Studies have revealed that quality services can surge present clients' retention, increase the attraction of new clients, rise profitability and minimized costs (Fassnacht et al., 2006). Eservice quality can rise client attractiveness and retention and can improve the online competitive advantages of organizations (Fassnacht et al., 2006).

Quality has been recognized as a main issue in certifying the success of online organizations in enticing and retentive clients. So it is essential to state what creates quality online organizations and a methodology for assessing the value of online organizations software.

\section{Summary of Website Assessment}

The common concerns found in the literature relating to website assessment are quality (e.g. Dran et al., 1999; Sohn and Tadisina 2008; Ha, 2016), Web design (e.g. Gehrke and Turban, 1999; Grimsley and Meehan, 2007; Osama et al., 2016) and usability (e.g. Agarwal and Venkatesh, 2002; Baker, 2007; Bouazza and Chebi, 2016). Researchers have recognized the Web quality concept from the quality of product or service (e.g. Karkin and Janssen, 2014; Karunasena and Deng, 2012). For example, Dran et al., (1999) approved Kano's Model of excellence as a hypothetical outline to assess the value of online organizations software. This model divided service quality into three levels based on client prospects: expected, normal, and exciting. The entrance level, "expected", states the least level of excellences that must be available on the online organizations. The second level, "normal" classifies the "wants" or the satisfiers because they are the ones that clienteles will specify as though from a list. They can either please or disgruntle the client based on their attendance or absence. The third level, "exciting", as defined by Kano, classifies the "wow" level qualities. These are likewise recognized as the "delighters" or "exciters" because they go well outside whatever the client might envisage. These investigators believe that service quality is not what the provider or seller put into it, but what the client receives from it. Therefore, a website should try to please its clients' needs to gain their loyalty.

Regarding to website design, Shneiderman (1997) brought an Objects/Actions Interface (OAI) model. This stimulates designers of a website to stress on investigating the correlation between the task and Web interface. Agarwal and Venkatesh (2002) viewed problems in website design from the perspective of network analysis. They recommended that attention must be taken while planning the Web site. Nielsen (1993) recommended five main groups that must be measured when planning a website for a business: navigation, business content, page loading, security, and efficiency and advertising/customer attention. They claimed that page loading is the greatest significant issue in website design. Grimsley and Meehan (2007) recommended changing the attention on assessing Web discrete pages to collected groups.

Performing a usability study typically needs client contribution, and occasionally the study needs to be piloted in a new environment. Nielsen (1995) provided rules and criteria to measure the usability of website design and recommended that every design project, including website development, must be subjected to usability analysis and other validation methods. Bouazza and Chebi (2016) also suggested that Web pages must be designed for usability and understanding. Nevertheless, a website with good usability cannot assurance users' preference (Tullis, 1998).

\section{Assessing and Analyzing Online Organizations Quality}

The measure of quality in information technologies has been a matter of concern for a long period of time. This matter has had a great deal of consideration from many scientists in the academic world. Lehman and Belady (1985) recognized a simple organization for information systems, being either E-type or S-type. An S-type system is one that is totally and fully well-defined, and is essential to be precise with respect to a mathematically defined requirement. An E-type system, in contrast, resolves to expectations of the system. An E-type system is precise when it pleases the operator expectations.

Organization of information systems in terms of its quality pointers, categorized quality to three viewpoints: 
service, process and product (Kumbhar, 2012). Numerous studies associated to the three viewpoints have created a number of measures for assessing informational systems like online organizations. These comprise information value (Gallagher, 1974), system practice (Srinivasan, 1985) and user gratification (Verdegem and Verleye, 2009).

The variety of these numerous measures was primarily a reason for worry, so Bailey and Pearson (1983) tried to blend them into an integrated model. The Model of "Information Services Success" (Bailey and Pearson, 1983) has been observed by numerous researchers as a main input (Palmer, 2002). Watson et al. (1998) proposed an adjustment to comprise a "Service Quality" module. Adjustment was certified by Delone (2003) composed with other changes combined to the updated Information Services Success Model.

Some academics have emphasized the problematic of insufficient measures for gauging the welfares of investments in IT (Palmer, 2002). There is a significant trouble in gauging the quality of informational systems. Still there is a need to gauge the success of online organizations (Alzahrani et al., 2016). One potential pointer is that of user gratification. Numerous sources have claimed that gauging gratification of users is beneficial as a replacement pointer of information system quality. The utilization of user gratification for gauging quality is argued in the next section.

\section{Use Satisfaction as a Real Measure}

User gratification progressively became a measure of website quality throughout the last four decades (Badri and Alshare, 2008). User gratification is defined as "the sum of one's feelings or attitudes toward a variety of factors affecting that situation (Bailey and Pearson, 1980).

The late 1980s witness a turning point with researches concentrating fully on user gratification with the software itself and features such as ease of use, timeliness, and content of the software (Doll and Torkzadeh, 1988).

A study of user gratification at IBM was built on usability, capability, reliability, maintainability, performance, and documentation features. During the 1990s, IBM used a group of user gratification models named, CUPRIMDSO, UPRIMDA, CUPRIMDA and UPRIMD, which denoted variously to dimensions of usability, capability, reliability, maintainability, performance, and documentation, installability, availability, service, and total gratification (Kan, 1995).

User gratification, currently referred to as customer satisfaction, is no doubt related to previous measures of software features, user friendliness or usability of software, and lately, website quality. In online organizations, interaction with the end-user is conducted through web based applications including both server and client-side applications generally referred to as a website. All user system communication is recognized through the interface, so it is self-evident that the quality of online organizations is directly related to the quality of the user interaction practice (Zwass, 1996).

Study by Wang (2003) has directly tied the assessment of an online organization website to customer gratification. An examination carried out by (Wang, 2003) on 35 online organizations in the United States recognized three approaches for evaluating quality. All three were really valuation of the gratification of the client.

The three main assessment approaches are text comments, categorized rating and overall rating. Text comment permits clients to write their own comments in 500 to 1000 characters. Characterized rating is attained with a survey that requests online clients to rank a number of quality factors using a gauge of 1 to $\mathrm{N}$ where $\mathrm{N}$ is the best score. The entire satisfaction ranking uses an ordinal ranking system with a scale of 1 to $\mathrm{N}$ where $\mathrm{N}$ is the best score. User gratification is a mixture of knowledge and awareness (Verdegem and Verleye, 2009). It has been revealed that numerous aspects can positively or negative influence a user's experience and their awareness of a website experience (Adepoju et al., 2016).

\section{Evaluating Online Organizations Website: A Review of Assessment Measures}

Online organization quality models - appearing in the late 1990s, subsequent the user satisfaction movement appeared as key measures of Online organization quality. One of the first models of website quality identified background, image size, sound file display, and celebrity endorsement as important features of software quality (Dreze and Zufryden, 1997). The web assessment method or WAM rapidly followed with quality features of external bundling, generic services, customer specific services, and emotional experience. In what promised to be the most prominent web quality model, attitude toward the site had quality features of informativeness and entertainment (Chen and Wells, 1999). The next major model was the e-satisfaction model with its five features of convenience, product offerings, product information, website design, and financial security.

The website quality model or WebQual for school portals was based on features of ease-of-use, experience, information, and communication and integration. An adaptation of the service quality or ServQual model, 
WebQual 2.0 measured quality features such as tangibles, reliability, responsiveness, assurance, and empathy (Nitin and Deshmukh, 2005).

Although some academics have tried to offer means of measuring online organizations specifically (e.g. Riadh, 2009), the collection of assessment criteria still needs additional theoretical explanation. A collection of e-service quality models is shown in Table 1; each of these has their points of strengths and weaknesses.

Table 1. E-Service Quality Models (Iham et al., 2013)

\begin{tabular}{|c|c|c|}
\hline No & Model & Weaknesses/ limitations \\
\hline 1 & $\begin{array}{l}\text { Technical and functional quality } \\
\text { model }\end{array}$ & $\begin{array}{l}\text { The model does not explain the method of } \\
\text { measuring technical and functional quality }\end{array}$ \\
\hline 2 & Gap model & $\begin{array}{l}\text { The model does not explain openly the } \\
\text { process of measuring the gaps at } \\
\text { diverse levels. }\end{array}$ \\
\hline 3 & Attribute service quality model & $\begin{array}{l}\text { It does not offer the assessment of service quality. } \\
\text { It does not offer a viable procedure to help management in } \\
\text { classifying the difficulties of service quality or defining feasible } \\
\text { means to increase the quality of service }\end{array}$ \\
\hline 4 & Performance only model & $\begin{array}{l}\text { The model requests to be universal for all service settings types. } \\
\text { Customer gratification and service quality connection needs to be } \\
\text { established }\end{array}$ \\
\hline 5 & $\begin{array}{l}\text { Perceived quality and } \\
\text { satisfaction Model }\end{array}$ & $\begin{array}{l}\text { The model does not highpoint how to attain and operate the service. } \\
\text { The model cannot deliver instructions for improving service quality }\end{array}$ \\
\hline 6 & $\begin{array}{l}\text { Retail service quality and } \\
\text { perceived value model }\end{array}$ & The model takes into consideration only value for money \\
\hline 7 & $\begin{array}{l}\text { Service quality, customer value } \\
\text { and customer satisfaction model }\end{array}$ & $\begin{array}{l}\text { The model required to be global for numerous service settings types. } \\
\text { Fewer items are used to assess the model variables. }\end{array}$ \\
\hline 8 & IT-based model & $\begin{array}{l}\text { Fewer items number is chosen for assessing the self-control feeling } \\
\text { and relief in using services based on IT. } \\
\text { Does not offer a service quality measure of transactions based on } \\
\text { IT. }\end{array}$ \\
\hline
\end{tabular}

Studies on online organizations quality similarly emphasis on more precise quality features like matters that permit positive transactions (Bidgoli, 2002) make best use of the perceived trustworthiness (Egger, 1998), or warrant online organizations reliability (Dustin et al., 2001). Though, all the above issues touch the quality of online organizations and are basics for their success, they are not the only ones that relate to online organizations quality. Iham et al., (2013) reached to assumption that there is no fully integrated method after their review of the literature. From these former lessons, it can be inferred that a universal approach, such as the one argued in this research, is needed inclusion all aspects touching quality.

\section{A Review of Current Methods to Assessing Online Organizations Software}

One of the first methods for gauging software quality was the practice of enumerating and measuring aspects of computer programs. Initial studies tried to count, qualify, and measure all of the aspects of software applications. Boehm et al., (1978) recognized the following attributes: usability, interoperability, flexibility, integrity, efficiency, maintainability, portability, reliability, testability, reusability, and correctness.

Throughout the 1970s and 1980s the measuring software aspects waned in favor of statistical models of website quality and reliability, which valued faults and mean time to failure. In contrast, throughout the 1990s, the practice of measuring software features began to take a position once over again in the form of website quality models. User satisfaction models were used to number end user attitudes towards software products (Iham et al., 2013).

Models of user gratification were finally approved by models of website quality last two decades. Simple website quality is defined as a “customer's judgment about the website's overall excellence or superiority, which is an attitude that comes from a comparison of expectations and perceived performance".

Most of the tools that have been established for the valuation of online organizations provide weight on the web applications of the system and they are based on reviews (Iham et al., 2013). This process offers important 
outcomes but requires additional period for data gathering and data analysis in all measurement phase.

The effort presented in this research, varies from questionnaire based studies in that it uses a technique aiming to limit bias and common faults in similar studies and delivers a flexible method to describe the quality of online organizations, as clients perceive it, in a short period.

\section{Predicting Quality of Online Organizations Software}

Assumed that the development of an online Organizations is essentially a software development effort; there are numerous principles that relate in governing the quality of such development. According to Dolan (2015), "there seems to be an almost overwhelming plenty of quality standards that lead to a high level of cynicism and uncertainty surrounding them and the eventual lack of use". Website designers want to use principles and best practices to make sure that websites are efficient, interoperable and accessible. Nonetheless many websites miss the mark to reach such objectives and no standard can openly estimate the quality of a website under construction is going to accomplish.

The software behind any Online Organizations is, in essence, the virtual organization and business operation of that site. It is thus rational to determine that the quality and assessment means of online organizations software will all the time rest on the quality of applications they comprise and their ability to achieve end-user requests.

Previous methods regarding the quality of online organizations software highlighted the usability values, using techniques like feature examination methods and gathering data about end-users' belief by surveys. These methods deliver an essential advice and their consequences are of valuable experience for upcoming work, though, they do not contribute straight to active model that allows forecasting (Dolan, 2015).

In this research, a model is projected where the features are of a active character. The outcomes resultant from the application of the suggested model are used to predict Online Organizations software quality and to guide the development of Online Organizations software in order to increase the quality measures, producing a software that provides an Online Organizations experience with a quality service and user gratification. Additionally, the outcomes resulting from its use are exploited for the model's continuous enhancement.

\section{Incentive for Applying Artificial Intelligent Method}

Having a metric for quality makes worries easier for online organizations, as it can then assess whether quality is being achieved. Seddon et al., (1999) describe quality as "a relative value that is significant only when compared to postulated values that are defined by the user or by standards organizations." Numerous researchers such as (Boehm et al., 1978) have then suggested universal quality models integrating a varied array of measures to describe a quality scheme. According to Iham et al., (2013), universal models such as these often require infrastructure to capture and analyze the data collected. Therefore, many enterprises look for simpler choices, like a single measure of quality, as contrary to process-driven quality.

Amrhein and Wang (2018) define a Bayesian Belief Network (BBN) as a model that describes numerous events, the dependencies among them, and the conditional probabilities in those dependences. Thus, a BBN is a network that represents the relationships of likelihoods among the factors (Amrhein and Wang, 2018). This evidence can then be utilized to compute the likelihoods of numerous potential reasons being the real cause of an occasion.

A BBN is used to model a domain comprising uncertainty in some way. The technology with which a system handles uncertain information forms is a vital component of its whole performance. The technologies for modeling uncertainty include Bayesian probability, Certainty Factor, Fuzzy Logic, and Dempster-Shafer theory. Bayesian probability uses probability theory to accomplish uncertainty by explicitly representing the conditional dependencies among the different knowledge components. It offers a language and calculus for reasoning about the beliefs in the presence of uncertainty. Prior probabilities are thus updated, after new events are observed to produce posterior probabilities. By reiterating this process, the implications of numerous source of evidence can be calculated in a consistent way, and the uncertainties are exploited explicitly to reach an objective conclusion. A $\mathrm{BBN}$ offers an instinctive graphical visualizing of the information including the connections between the several causes of ambiguity.

An outline for measuring the qualities of online organization software is the essence of this study. At present, the question is: 'Can a Bayesian Belief Network be beneficial to predict quality levels of the online organization software and the aspects behind that level of excellence?' According to Amrhein and Wang (2018), in using a BBN, a solo model can be used for both analytic and causal cognitive. This recommends that a BBN could be used to steadily forecast the qualities of online organization software during development and to choose the causes for the anticipated quality. 


\section{A BBN Prototype Model for Online Organization Software}

Though there is inadequate space to fully explain the development of a BBN model. A sample of BBN model was developed to illustrate their beneficial properties. The viewpoint behind the BBN model is the creation of a network that focuses and utilized the information gained from the examination of data collected through earlier studies as well as uses its own results for future estimations.

Figure 1 shows a presentation of the network. The model uses nodes to represent the quality factors, characteristics and sub-characteristics of online organization. Each node is characterized by a set of possible states called evidence and is linked to its parent nodes by directed arrows. In figure 1 the node 'Quality' signifies the online organization software quality as a full and is described by three possible states (evidence): 'Good, 'Average, and 'Poor. Each quality factor node is linked to the corresponding online organization software quality features. Lastly, all of these quality dimensions are linked to a number of child nodes encompassing the quality sub-factors of online organization software.

MSBNx tool is a component-based windows application for generating, measuring, and gauging BBNs; developed at Microsoft Research. Figure 1 is a screenshot of the Model Diagram window with the model developed. The model drawing window is the main document of MSBNx. Figure 2 is the model assessment window, which is the primary means of performing inference using a model. There are two primary sections of the evaluation window. The left-hand pane contains a tree-based view of the nodes. The right-hand pane contains a tabbed display of the results of inference presented in several ways.

Furthermore, the MSBNx instrument offers two forms of propagation: sum and max. The instrument computes the factor availability depending on the evidence established in the node probability table. This is a table for all nodes that keeps all the potential combinations of this availability number. These availabilities can be modified as extra info collected so that the instrument can re-calculate the complete probabilities based on new facts.

In the case of quality evaluation, the evidence can be gathered from failure data, the experience in developing similar systems, architectural details of the design, etc. The more evidence was gathered, the more accurate the model was in predicting the quality level and determining the main factors that affect the calculated quality level.

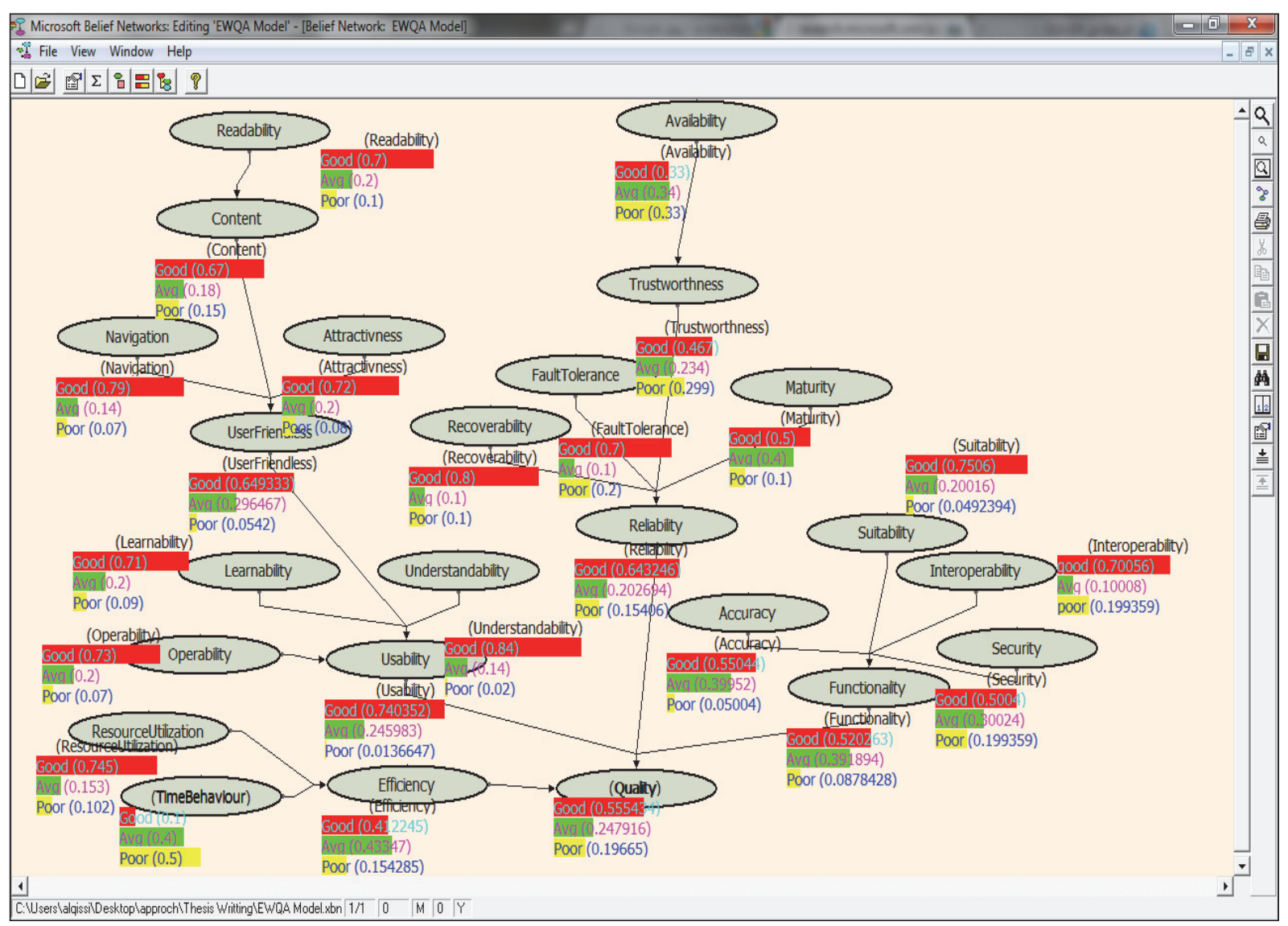

Figure 1. Screenshot of MSBNx (Model Diagram Window) 


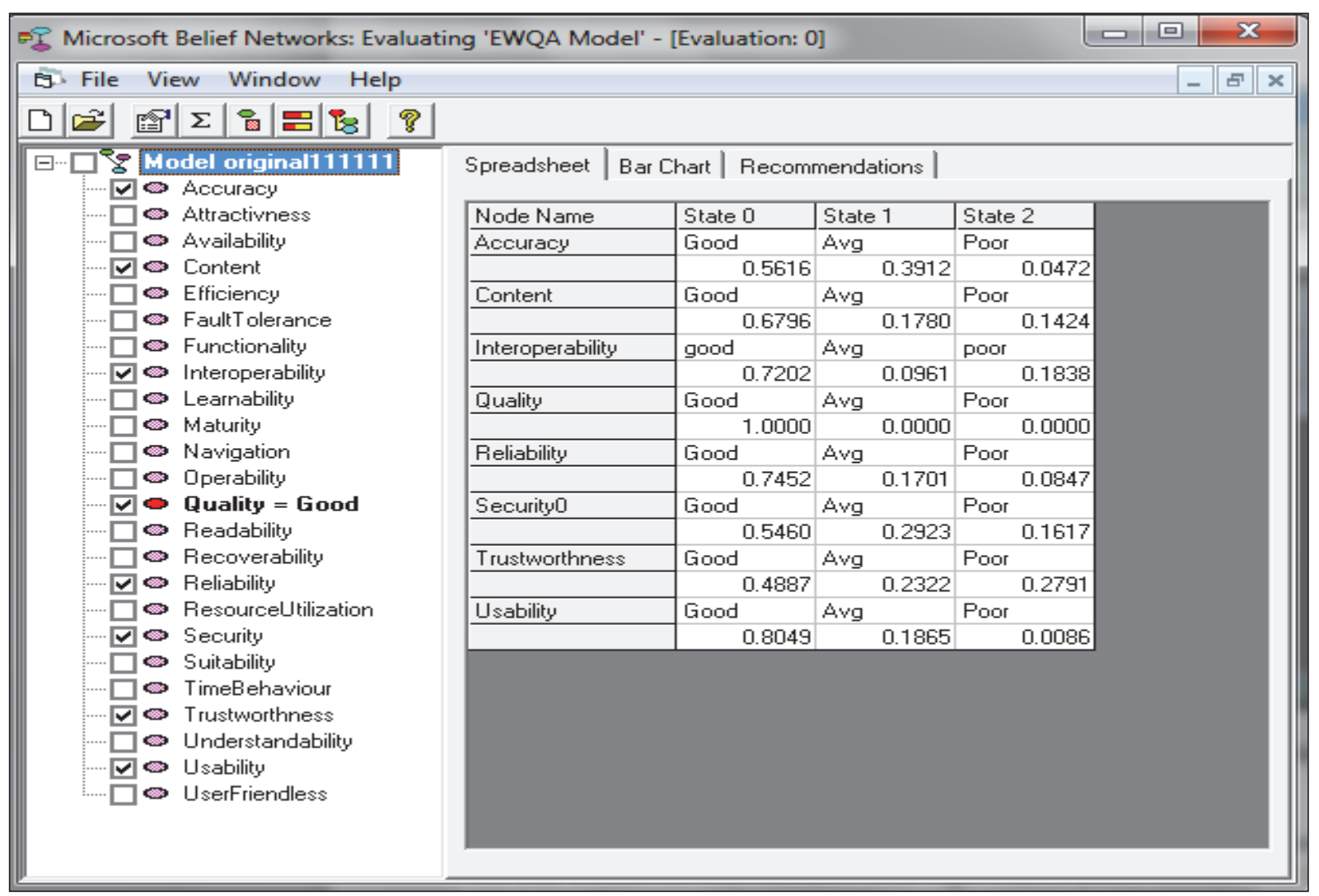

Figure 2. Model Evaluation Window

\section{BBN Model Uses}

Although the means in which a BBN can be used is unlimited, four forms of practice approaches for BBN model have been recognized:

\section{Prediction of Quality dimensions}

In this kind of usage - as much evidence gathered and plugged into BBN - The model can calculate all the factors that have not been entered. This can provide an impression of the level of quality and unveil complications, if any, in the developing software. For instance, assume the user has the evidence given in Table 2 about some observable nodes, the user then can plug this data into BBN model to forecast the quality level and reveal difficulties, if any.

According to BBN model, the outcomes offer a forecast, with $71 \%$ likelihood that the software is user friendless, and $61 \%$ it lacks functionality and $40 \%$ quality for the software, which reveals inacceptable quality level.

Table 2. Observable node assessment

\begin{tabular}{ll}
\hline Nodes & Assessment \\
\hline Readability & Good \\
Navigation & Good \\
Availability & Good \\
Fault Tolerance & Average \\
Accuracy & Average \\
Security & Poor \\
\hline
\end{tabular}




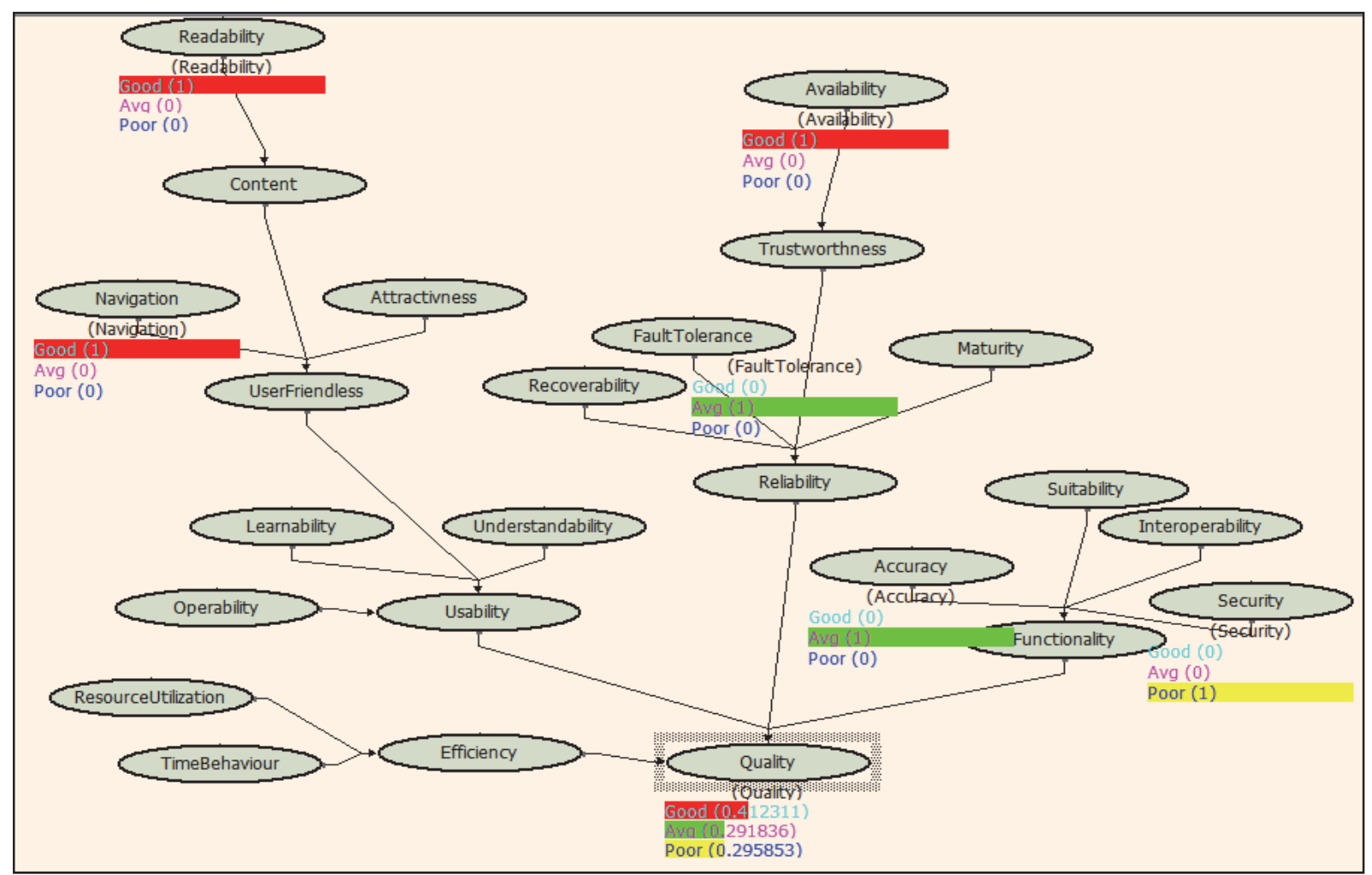

Figure 3. BBN Model to predict quality dimensions

\section{Analytical Use}

BBN model may be used as an analytical tool in order to find possible reasons for complications. For example, Usability is not satisfactory as presented in Figure-4, Using BBN model; the user can discovery that Understandability and Operability are the reasons of this problematic. Changing the Understandability and Operability in to a good state will stimulate the Usability to a higher level, as displayed in Figure 5 below.

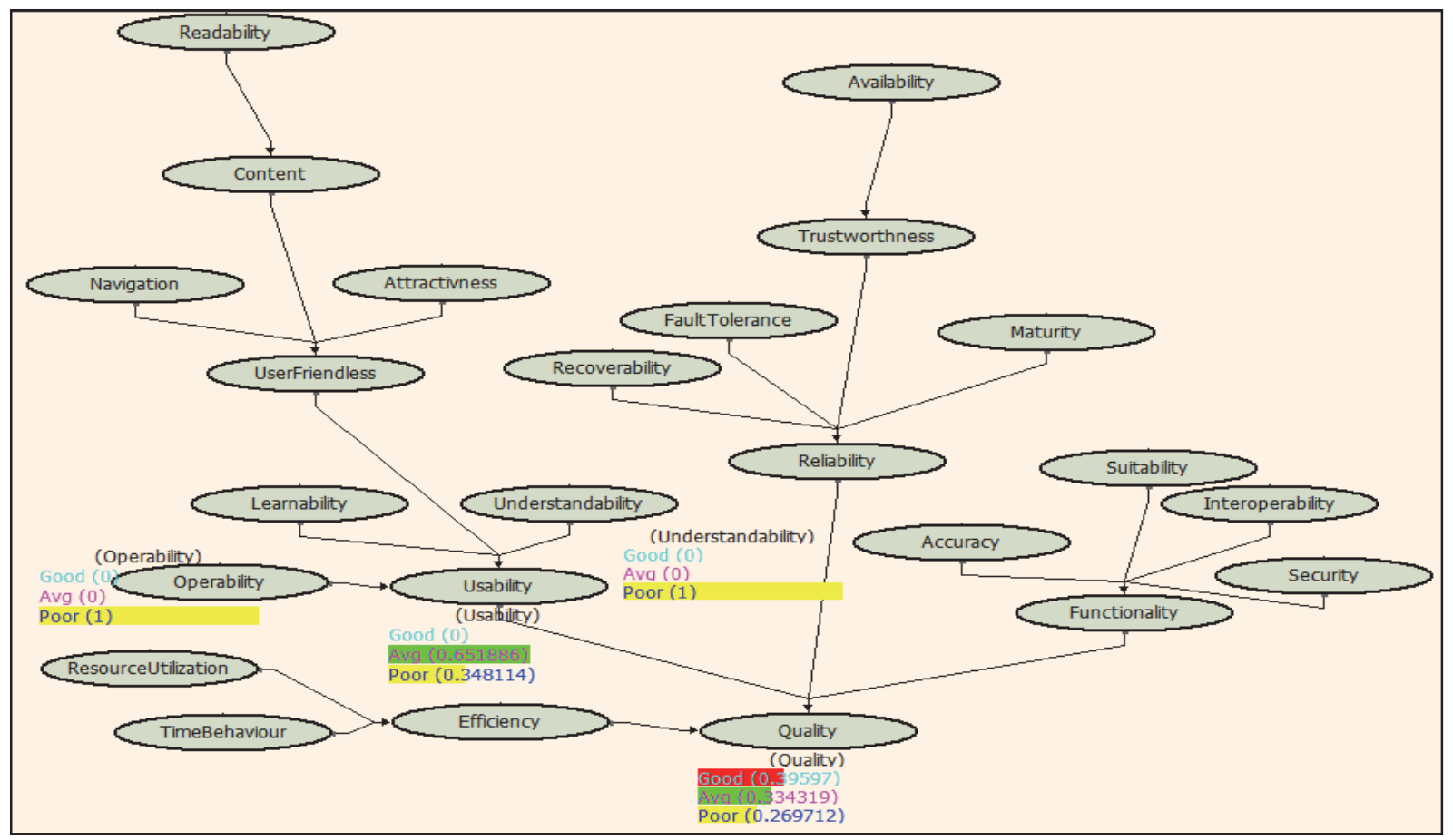

Figure 4. Unsing BBN Model as an analytical tool 


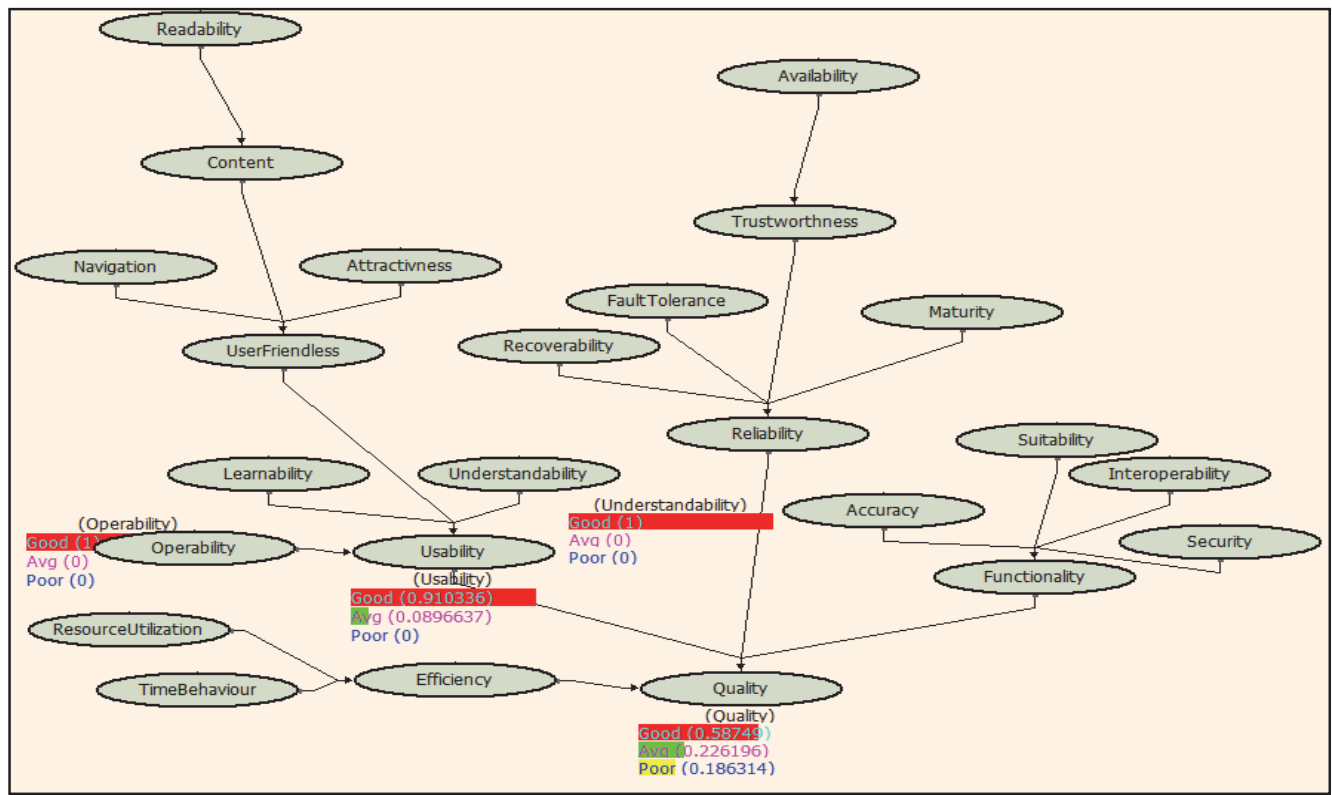

Figure 5. Result of changing Understandability and Operability status to good

\section{Impact Analysis}

A different approach to use BBN model is to assess the consequences of the future variations in the observable nodes on the intermediate nodes plus the target node (Quality). In this approach, the probable future statuses for the observable nodes are entered. Then BBN model computes the intermediate nodes plus the target node (Quality) i.e. likely for such modifications on the observable node. The user can explore what will occur if the status of Involved Capacity altered from average to good as displayed in Figure 6.

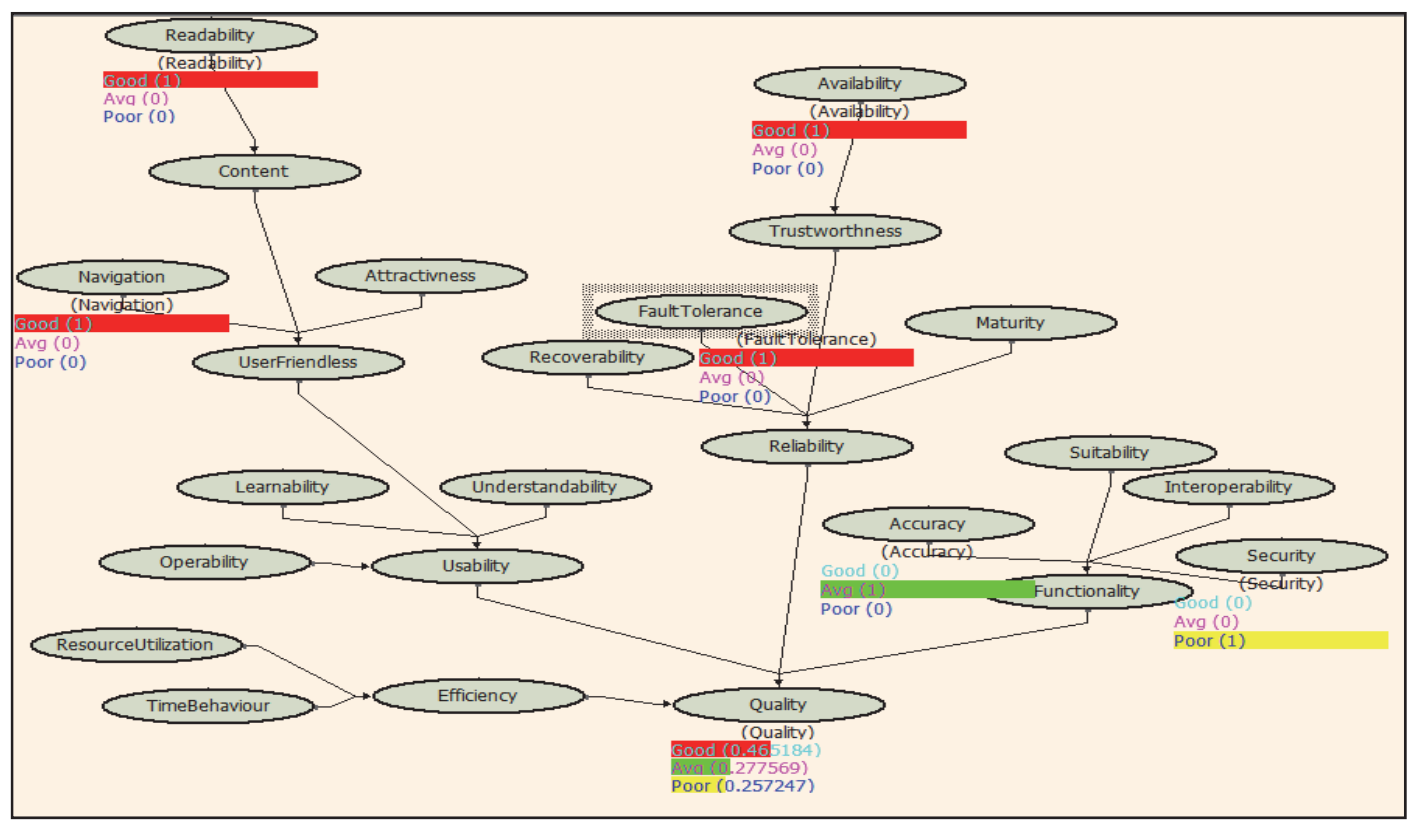

Figure 6. Result of altering the Status of Involved Capacity from average to good

\section{Quality Aspect Satisfaction}

Entering visions about intermediate nodes into the BBN model can help software developer to control which aspects must to pay attention during the development process. The probabilities for all the observable nodes are then computed. If, for instance, the project has to be extremely usable, Maintainability, User-Friendliness, 
Efficiency, and Navigability probably may be given a high probability as presented in Figure 7.

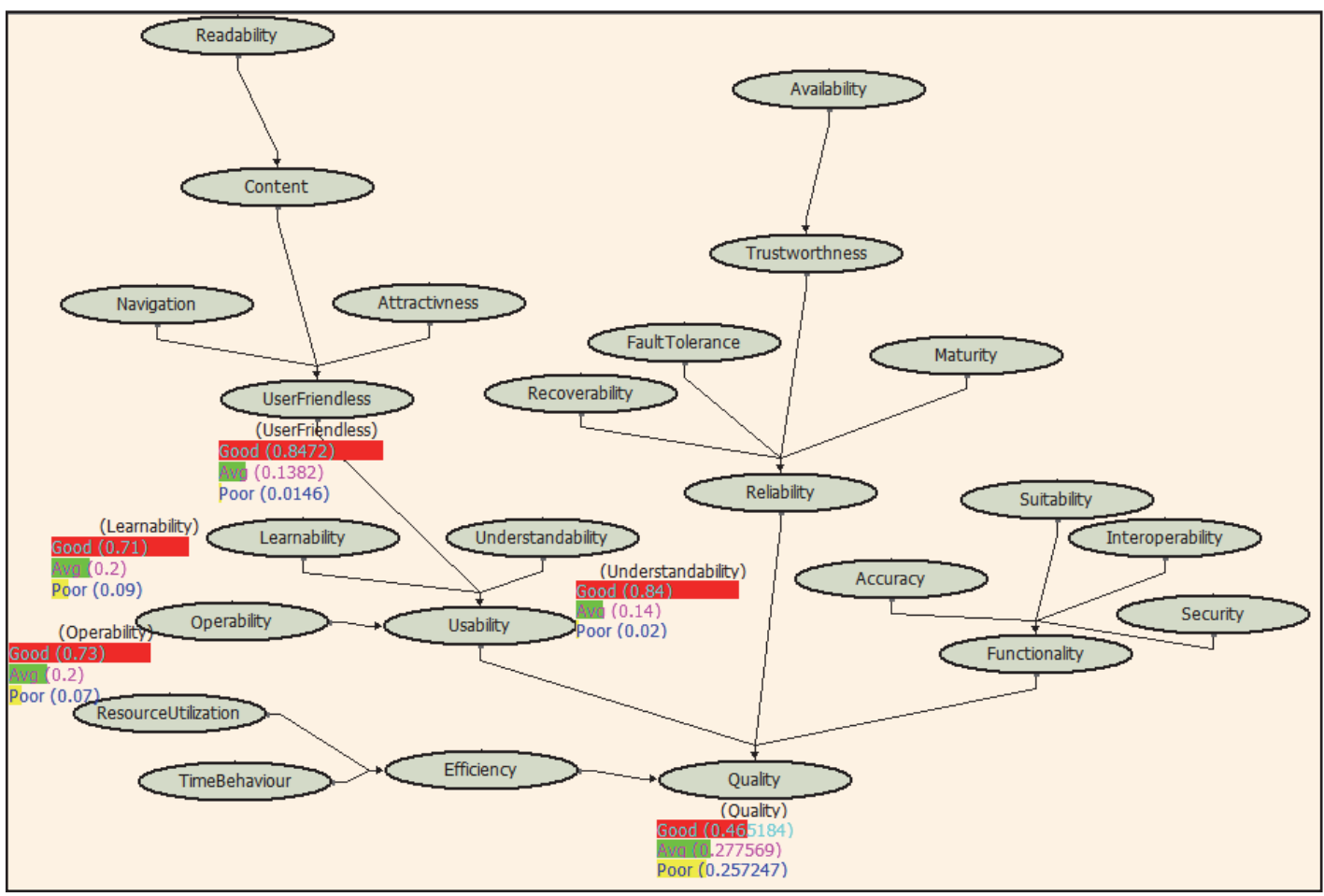

Figure 7. Ensure contentment of quality aspect

This evidence can aid in cases where aspects that were under severe concern are graded nearby the bottom of the precedence list; these can be detached from consideration, therefore saving valued development assets. Depend on this likelihood; the project team must give these quality aspects more attention throughout the development process in order to produce a highly usable system.

The four practice approaches may be used in mix. For instance, quality factor estimate usage can disclose complications (analytical usage). This might be the commencement to do impact analysis for resolutions for the noticed difficulties. On the other hand, if there are a lot of complications, the quality aspect satisfaction approach might be used to realize exactly how much the perfect quality level varies from the real level.

\section{Conclusions}

Abundant of the available experiential effort in the quality of e-service field is well in advance of the unfounded rhetoric sadly typical of much of what passes for software engineering study. Nevertheless, all discipline must obtain as much, if not more, from its failures as its achievements. In this soul, the literatures were studied with a vision to better realize previous failures and plan potential opportunities for forthcoming achievement.

The appraisal conducted for the e-service quality models has shown that numerous tools that have been established for the valuation of e-service quality offer emphasis on the web applications of the system and they are based on reviews. This method delivers important outcomes but it requires additional period for data collection and data examination in all measurement stages.

In this research, we recommend a universal model for e-service quality valuation, via BBN, as an extra method to the single-issue models used at present. This model varies from questionnaire-based surveys approaches in that it uses a process aiming to limit bias and common mistakes as well as provides a flexible way to define the quality of e-services, as users perceive it, in a short period.

\section{Acknowledgments}

This research was supported by The University of Jordan.

\section{References}

Adepoju, S., Shehu, I., \& Baker, P. (2016). Accessibility evaluation and performance analysis of e-government websites in Nigeria. Journal of Advances in Information Technology, 7(1), 49-53. 
Agarwal, R., \& Venkatesh, V. (2002). Assessing a firm's Web presence: A heuristic evaluation procedure for the measurement of usability. Information Systems Research, 13(2), 168-186. Https://doi.org/10.1287/isre.13.2.168.84

Alzahrani, L., Al-Karaghouli, W., \& Weerakkody, V. (2016). Analysing the critical factors influencing trust in egovernment adoption from citizens' perspective: A systematic review and a conceptual framework. https://doi.org/10.1016/j.ibusrev.2016.06.004

Amrhein, J., \& Wang, F. (2018). Bayesian Concepts: An Introduction. Proceedings of SAS Global Forum 2018. Paper 1863 - 2018. Denver, Colorado. SAS Institute, Cary NC.

Badri, M. A., \& Alshare, K. (2008). Path analytic model and measurement of the business value of e-government: An international perspective. International Journal of Information Management, 28(6), 524-535.

Baker, D. L. (2007). Website usability of the most populous counties in the United States. Journal of E-government, $3(3), 65-89$.

Bedman, N. (2015). Perceived service quality and satisfaction of self-service technology, International Journal of Quality \& Reliability Management, 32(4), 361.

Bidgoli, H. (2002). Electronic Commerce Principles and Practice, Academic Press. San Diego.

Boehm, B. W., Brown, J. R., \& Kaspar, J. R. (1978). Characteristics of Software Quality. TRW Series of Software Technology, Amsterdam, North-Holland Publishing Company.

Bouazza, A., \& Chebi, H. (2016). Digital governance: A usability study of Omani e-government websites. In S. I. Singh (Ed.), Trends, prospects, and challenges in Asian e-governance (pp. 56-74). New York, NY: Information Science Reference.

Chen, Q., \& Wells, W. D. (1999). Attitude toward the site. Journal of Advertising Research, 39(5), 27-37.

Delone, W. (2003). The Delone and McLean Model of Information Systems. Journal of Management Information System, 19(4), 9-30.

Dolan, T. (2015). A six-dimensional assessment tool for e-government development applied to homepage sites of 25 U.S States. In C. Adams (Ed.), Proceedings of the 15th European Conference on eGovernment 2015: ECEG 2015 (- 92). Reading, UK: Academic Conferences and Publishing International Ltd.

Doll, W. J., \& Torkzadeh, G. (1988). The measurement of end user computing satisfaction. MIS Quarterly, 12(2), 258-274. https://doi.org/10.2307/248851

Dran, G. M., Zhang, P., \& Small, R. (1999). Quality Web sites: an application of the Kano model to Web-site design. Paper presented at the Fifth Americas Conference on Information Systems. Milwaukee USA.

Dreze, X., \& Zufryden, F. (1997). Testing web site design and promotional content. Journal of Advertising Research, 37(2), 77-91.

Dustin, E., Rashka, J., McDiarmid, D., \& Neilson, J. (2001). Quality Web Systems, Performance, Security, and Usability, Addison -Wesley. New York.

Egger, F. N. (1998). Increasing Consumers' Trust in Electronic Commerce through Human Factors Engineering. Master of Science (Ergonomics) Thesis, University of London.

Fassnacht, Martin and Ibrahim Koese (2006). Quality of Electronic Services Conceptualizing and testing a Hierarchical Model. Journal of Service Research, 9(1), 19-37.

Gallagher, C.A., (1974). Perceptions of the Value of a Management Information System. Academy of Management Journal, 46-55. https://doi.org/10.2307/254770

Gehrke, D., \& Turban, E. (1999). Determinants of successful Web-site design: relative importance and recommendations for effectiveness. Paper presented at the Proceedings of the 32nd Hawaii International Conference on system Sciences. Hawaii USA.

Grimsley, M., \& Meehan, A. (2007). E-government information systems: Evaluation-led design for public value and client trust. European Journal of Information Systems, 16(2), 134-148.

Iham, T., Mahmood, A. K., \& Tang, J. L. (2013). A review of e-service quality dimensions in user satisfaction, 3rd International Conference on Research and Innovation in Information Systems - ICRIIS' 13.

Kan, S. H. (1995). Metrics and models in software quality engineering, Addison-Wesley.

Karkin, N., \& Janssen, M. (2014). Evaluating websites from a public value perspective: A review of Turkish local 
government websites. International Journal of Information Management, 34, 351-363.

Karunasena, K., \& Deng, H. (2012). Critical factors for evaluating the public value of e-government in Sri Lanka. Government Information Quarterly, 29(1), 76-84.

Kumbhar V. M. (2012). Conceptualization Of E-Services Quality And E-Satisfaction: A Review of Literature. Management Research and Practice, 4(4), 12-18.

Lehman, M., \& Belady, L. A. (1985). Program Evolution, Processes of Software Change, Acad. Press, London.

Nielsen, J. (1993). Usability engineering, San Diego, CA: Academic Press.

Nielsen, J. (1995). Multimedia and hypertext: The Internet and beyond, AP Professional, Boston.

Nitin, S., \& Deshmukh, S. G. (2005). Service quality models: a review. International Journal of Quality \& Reliability Management, 22(9), 913-949. Emerald Group Publishing Limited 0265-671X. https://doi.org/10.1108/02656710510625211

Osama Mohammad Rababah, Mohammad Alshraideh, Mohammad A. M. Abushariah, Saher Manaseer and Maged AlQisi, (2016). Optimizing the process of developing E-government website using decision support system, Scientific Research and Essays, 11(10), 104-116.

Palmer J., (2002). Web Site Usability, Design, and Performance Metrics. Information Systems Research, 13(2), 151-167. https://doi.org/10.1287/isre.13.2.151.88

Pearson, S. W., and Bailey, J. E. (1980). Measurement of computer user satisfaction. ACM SIGMETRICS Performance Evaluation Review, 9(1), 9-68.

Riadh, L. (2009). A review of twenty years Of SERVQUAL research. International Journal of Quality and Service Sciences, 1(2), 172-198. Emerald Group Publishing Limit.

Saha S, Nesa Z (2011). Measuring service quality: a comparative assessment based on customer service of HSBC and DBBL. Journal of Banking \& Financial Services, 5, 111-127.

Sara, J., Md. Salamun, R., \& Bin, L. (2018). Assessing The E-Services of the Banking Sector by Using E-Servqual Model. Journal of Internet Banking and Commerce, April 2018, 23(1).

Seddon, B., Staples, S., Patnayakuni, R., \& Bowtell, M. (1999). Dimensions of Information Systems Success. Communications of AIS 2. Association for Information Systems Atlanta, GA, USA, 2(3), Article No. 5.

Shneiderman, B. (1997). Designing information-abundant Web sites: issues and recommendation. HumanComputer Studies, 47, 5-29. https://doi.org/10.1006/ijhc.1997.0127.

Sohn, C., \& Tadisina S. K. (2008). Development of e-service quality measure for internet-based financial institutions. Total Quality Management and Business Excellence, 19, 903-918.

Srinivasan, A., (1985). Alternative Measures of System Effectiveness: Associations and Implications. MIS Quarterly, 9, 243-253. https://doi.org/10.2307/248951

Tullis, T. S. (1998). A method for evaluating Web page design concepts, Paper presented at the ACM SIGCHI Conference on Human Factors in Computing Systems, Los Angeles USA, ACM Press, pp. 115-120.

Verdegem, P., \& Verleye, G. (2009). User-centered e-government in practice: A comprehensive model for measuring user satisfaction. Government Information Quarterly, 26(3), 487-497.

Wang, M. (2003). Assessment of E-Service Quality via ESatisfaction in E-Commerce Globalization. Retrieved from http://www.ejisdc.org/ojs2/index.php/ejisdc/articl e/view File/68/68

Watson, R. T., Pitt, L. F., \& Kavan, C. B. (1998). Measuring Information Systems Service Quality: Lessons form two longitudinal case studies. MIS Quarterly, 22(1), 61-79. https://doi.org/10.2307/249678

Zwass, V. (1996). Electronic commerce: structures and issues. International Journal of Electronic Commerce, 1, $3-23$.

\section{Copyrights}

Copyright for this article is retained by the author(s), with first publication rights granted to the journal.

This is an open-access article distributed under the terms and conditions of the Creative Commons Attribution license (http://creativecommons.org/licenses/by/4.0/). 